\title{
PENGARUH KESEHATAN DAN KESELAMATAN KERJA (K3) TERHADAP KINERJA KARYAWAN PABRIK KELAPA SAWIT DI PT. DSN
}

\section{THE EFFECT OF OCCUPATIONAL HEALTH AND SAFETY (K3) ON THE PERFORMANCE OF PALM OIL MILL EMPLOYEES AT PT. DSN}

\author{
Mohamad Ali Widodo", Erna Rositah¹, Budi Winarni ${ }^{*}$ \\ ${ }^{1}$ Politeknik Pertanian Negeri Samarinda, Kampus Gunung Panjang, Jl. Samratulangi, \\ Samarinda, Indonesia \\ *corresponding bwinarni14@gmail.com
}

\begin{abstract}
This research is based on the importance of applying occupational health and safety to employees of palm oil mills, It is worth noting that by providing awareness to factory employees about occupational health and safety will improve the performance of these employees. The purpose of this research is to know the characteristics of factory employees in the production section and the influence of occupational health and safety on the performance of employees of palm oil mills production parts.

The time and place of this research was conducted on December 2 to December 21, 2020 and took place at PT. DSN and located in Muara Wahau District. The research method used is quantitative by using the dissemination of statement questionnaires with variables of health, safety, and employee performance. Researcher data processing techniques use validity tests, reliability tests, and multiple linear regression analysis through spss 22 applications.

From the results of research activities that have been conducted by researchers obtained data that shows that there is a positive and significant influence between occupational health and safety variables to the performance variables of factory employees.
\end{abstract}

Keywords: occupational health, occupational safety, and employee performance.

\section{PENDAHULUAN}

Industri sering berkaitan dengan sumber daya manusia (SDM) dimana teknologi dikendalikan dan digunakan oleh manusia, contohnya adalah pabrik. Pabrik merupakan suatu bangunan industri besar dimana para pekerja mengolah barang atau mengawasi pemrosesan mesin dari suatu produk menjadi produk lain sehingga mendapat nilai tambah dari produk tersebut (Anonim, 2016).

PT. DSN merupakan perusahaan yang bergerak di bidang perkebunan kelapa sawit yang berdiri sejak tahun 1980. Pada tahun 2016 PT. DSN membangun Pabrik Kelapa Sawit (PKS) yang ke 6 , letak pabrik tersebut berada di Kecamatan Muara Wahau. Pabrik ini juga memiliki beberapa pemrosesan hingga menjadi minyak Crude Palm Oil (CPO), yaitu mulai dari proses jembatan timbang, penyortiran buah buah (loading ramp), proses perebusan buah (sterilizer), proses penebah (threser process), proses pemurnian minyak (clarification station), dan pengolahan biji (kernel station) (Anonim, 2018).

Dalam industri pabrik pada bidang perkebunan yang perlu diketahui bahwa terdapat hubungan yang berkaitan dengan kesehatan dan keselamatan kerja (K3) terhadap kinerja karyawan, salah satunya di bagian proses produksi CPO yang menyangkut pekerjaan mengenai kesehatan dan keselamatan kerja bagi karyawan untuk menjaga dan melindungi diri dari adanya bahaya kecelakaan kerja yang akan terjadi. Melalui upaya-upaya pengendalian semua bentuk kerjanya bila potensi bahaya telah terkendali dan memenuhi batas standar aman, kondisi lingkungan kerja yang aman, sehat dan 
proses produksi menjadi lebih lancar (Suardi, 2007).

Berdasarkan penguraian latar belakang di atas, maka permasalahan yang akan dikaji dan dibahas dalam penelitian ini adalah bagaimana pengaruh kesehatan dan keselamatan kerja terhadap kinerja karyawan pabrik kelapa sawit di PT. DSN.

Supaya tidak menyimpang dari permasalahan yang akan dibahas, maka peneliti mempunyai batasan-batasan masalah yaitu, objek untuk pengambilan data diarahkan pada informasi yang diberikan perusahaan serta karyawan produksi di PKS 6, dan untuk pengambilan data menggunakan kuesioner pertanyaan seputar kesehatan dan keselamatan kerja dan kinerja.

Adapun tujuan dari penelitian ini adalah untuk mengetahui karakteristik karyawan pabrik bagian produksi dan pengaruh kesehatan dan keselamatan kerja (K3) terhadap kinerja karyawan pabrik kelapa sawit bagian produksi.

Adapun hasil yang diharapkan dari penelitian ini adalah sebagai bahan evaluasi dan informasi bagi perusahaan untuk mengontrol kesehatan dan keselamatan kerja bagi perusahaan serta kinerja karyawan dalam bekerja, kemudian untuk dapat meminimalkan tingkat kecelakaan kerja dan meningkatkan kinerja karyawan.

\section{METODOLOGI}

\section{Tempat dan Waktu Penelitian}

Penelitian pengaruh kesehatan dan keselamatan kerja (K3) terhadap kinerja karyawan pabrik kelapa sawit bagian produksi di PT. DSN dan berlokasi di Kecamatan Muara Wahau Kabupaten Kutai Timur. Penelitian dilakukan selama 20 hari yaitu dimulai pada tanggal 2 sampai dengan 21 Desember 2020.

\section{Alat dan Bahan Penelitian}

Alat yang digunakan dalam penelitian ini adalah laptop yang dilengkapi dengan software Microsoft Office 2010, SPSS versi 22, kamera smartphone, serta alat tulis. Sedangkan bahan yang digunakan untuk penelitian adalah kuesioner penelitian yang berisi pertanyaan seputar K3 dan kinerja karyawan.

\section{Sumber Data}

Dalam kegiatan penelitian ini penulis menggunakan dua jenis sumber data yaitu:

1. Data primer

Data yang diperoleh dari lapangan secara langsung dari sumber kuesioner yang disebarkan oleh peneliti kepada karyawan serta wawancara secara langsung.

2. Data sekunder

Data yang diambil melalui buku-buku, dokumentasi kegiatan dan data-data dari perusahaan, serta referensi yang berhubungan dengan judul yang diambil oleh peneliti.

\section{Prosedur Kerja}

Untuk memperoleh data, peneliti membuat sejumlah kuesioner pernyataan agar kemudian bisa diolah. Berikut ini prosedur kerja yang ada dalam pelaksanaan penelitian:

1. Tahapan persiapan untuk melaksanakan penelitian dengan mendatangi objek perusahaan PT. DSN.

2. Peninjauan di lapangan secara langsung untuk mengetahui jumlah karyawan atau sampel pengambilan data sekunder..

3. Melakukan wawancara secara langsung, dokumentasi dan pengambilan data sekunder dari bukubuku serta literatur perusahaan, setelah itu pemberian kuesioner pernyataan seputar K3 dan kinerja karyawan.

4. Data atau hasil yang telah diperoleh dari lapangan (kuesioner) akan dan didukung dengan laptop yang berisikan software Microsoft Office 2010, dan SPSS 22. Setelah itu akan dilakukan analisis atau pembahasan mengenai hasil yang diperoleh. 


\section{Teknik Analisis Data}

Dari hasil data yang telah dikumpulkan, penulis mengolah data dengan menggunakan analisis kuantitatif, yaitu analisis yang menginterpretasikan dalam bentuk angka-angka dan digunakan sebagai alat statistik sehingga mempermudah dalam menafsirkan data mentah yang diperoleh. Dalam kegiatan analisis ini meliputi:

1. Sampel

Sampel merupakan bagian dari populasi yang diambil melalui cara-cara tertentu yang juga memiliki karakteristik tertentu (lqbal, 2002). Untuk menentukan jumlah responden yang akan diambil, digunakan pengambilan sensus. Jika populasinya kurang dari 100 orang, maka jumlah respondennya diambil secara keseluruhan, tetapi jika populasinya lebih dari 100 orang maka, diambil 10$15 \%$, atau $20-25 \%$ dari jumlah populasinya (Arikunto, 2013). Dalam penelitian ini dilakukan pengambilan responden secara keseluruhan sebanyak 38 orang dalam karyawan bagian produski di PKS 6.

2. Uji Validitas

Menurut Buhono (2005), menilai dari butir-butir pertanyaan dapat dilihat dari nilai corrected itemtotal. Suatu butir pertanyaan dikatakan valid jika nilai r-hitung yang merupakan nilai dari corrected item-total correlation > dari r-tabel dengan taraf kesalahan $10 \%$ atau 0.1 untuk menguji valid tidaknya pertanyaan dapat dilakukan melalui program computer Excel Statistic Analysis dan SPSS.

3. Uji Reliabilitas

Menurut Buhono (2005), pertanyaan atau konstruk akan disusun dalam bentuk kuesioner dan digunakan dengan alat ukur Cronbach Alpha melalui program computer Excel Statistic Analysis dan SPSS. Suatu variabel dikatakan baik (reliabel) apabila memilik nilai Cronbach Alpha lebih dari 0.60 .
4. Analisis Regresi Linear Berganda

Menurut Sugiyono (2016), uji analisis regresi linear berganda merupakan suatu regresi yang memiliki satu variabel dependen (teikat) dan dua atau lebuh variabel independen (bebas). Analisis ini digunakan untuk mengetahui pengaruh dari independen $\left(\mathrm{X}_{1}, \mathrm{X}_{2}\right)$ terhadap variabel dependen (Y) dengan model regresi:

$$
Y=\beta 0+\beta_{1} X 1+\beta_{2} X 2+e
$$

Keterangan:

Y : Variabel dependen

$\beta 0$ : Konstanta

$\beta_{1}, \beta_{2}$ : Koefesien regresi

e : Standar eror

$\mathrm{X}_{1} \quad$ : Kesehatan kerja

$\mathrm{X}_{2}$ : Keselamatan kerja

5. Uji F (Simultan)

Uji $F$ digunakan untuki mengetahui pengaruh secara bersama-sama dari dua variabel bebas dengan variabel terikat secara bersamaan. Apabila $F_{\text {hitung }}<F_{\text {tabel }}$ maka variabel bebas tidak memiliki pengaruh terhadap variabel terikat. Taraf kesalahan $\mathrm{X}_{1}, \mathrm{X}_{2}$ yang digunakan adalah $5 \%$ atau 0,05 . Jika $F_{\text {hitung }}>F_{\text {tabel }}$ maka dapat disimpulkan variabel bebas signifikan secara serentak dengan variabel terikat.

6. Koefesien Determinasi Menurut Kuncoro (2013), uji koefesien determinasi atau $\mathrm{R}^{2}$ digunakan untuk mengukur seberapa jauh kemampuan variabel bebas menerangkan variabel terikatnya. Nilai koefesien determinasi berada pada rentang angka 0-1. Jika angka koefesien determinasi mendekati angka 0 berarti kemampuan variabel bebas yang diberikan kepada variabel terikatnya sangat lemah, sedangkan jika mendekati angka 1 maka akan semakin kuat.

Dalam melakukan pembuatan kuesioner pernyataan yang akan diberikan kepada karyawan perlu adanya pembobotan dari setiap pernyataan dengan penilaian dari 
kuesioner atau dengan demikian ada 5 bobot atau nilai yang diberikan peneliti untuk pertanyaan kuesioner yaitu:

Tabel 1. Bobot Nilai Kuesioner

\begin{tabular}{lc}
\hline \multicolumn{1}{c}{ Jawaban } & Bobot \\
\hline Sangat Tidak Setuju (STS) & 1 \\
Tidak Setuju (TS) & 2 \\
Kurang Setuju (KS) & 3 \\
Setuju (S) & 4 \\
Sangat Setuju (SS) & 5 \\
\hline \multicolumn{2}{c}{ Untuk mengetahu adanya } \\
pengaruh antara kesehatan dan \\
keselamatan Kerja terhadap kinerja \\
karyawan pabrik, maka dapat ditarik \\
sebuah hipotesis sebagai berikut: \\
Hilabel \\
kerdapat pengaruh antara variabel \\
terhadap kinerja karyawan \\
pabrik.
\end{tabular}

$\mathrm{H}_{0}$ :Tidak terdapat pengaruh antara variabel kesehatan, keselamatan, dan variabel kinerja karyawan pabrik.

\section{HASIL DAN PEMBAHASAN}

\section{Hasil}

\section{Karakteristik Responden}

Gambaran umum responden ini bertujuan untuk mengetahui karakteristik dari karyawan, penggolongan responden ini berdasarkan pada usia, tingkat pendidikan, dan lama bekerja.

Tabel 2 Karakteristik Responden Berdasarkan Usia.

\begin{tabular}{cccc}
\hline No & Umur & Jumlah & Persentase \\
\hline 1 & $<20$ Tahun & 0 & $0 \%$ \\
2 & $20-29$ Tahun & 27 & $71,1 \%$ \\
3 & 30-39 Tahun & 10 & $26,3 \%$ \\
4 & 40-50 Tahun & 1 & $2,6 \%$ \\
5 & $>50$ Tahun & 0 & $0 \%$ \\
\hline & Total & 38 & $100 \%$ \\
\hline
\end{tabular}

Berdasarkan Tabel 2, dapat dilihat bahwa responden banyak yang didominasi oleh karyawan yang berusia
20-29 tahun yaitu dengan jumlah sebanyak 27 orang dari 38 responden $(71,1 \%)$.

Tabel 3 Karakteristik Responden Berdasarkan Tingkat Pendidikan

\begin{tabular}{cccc}
\hline No & Pendidikan & Jumlah & Persentase \\
\hline 1 & SD & 0 & $0 \%$ \\
2 & SMP & 0 & $0 \%$ \\
3 & SLTA & 32 & $84,2 \%$ \\
4 & D III/S 1 & 6 & $15,8 \%$ \\
\hline & Total & 38 & 100 \\
\hline
\end{tabular}

Berdasarkan Tabel 3, data tingkat pendidikan di atas menunjukkan bahwa sebagian besar responden memiliki latar belakang lulusan SLTA yaitu dengan jumlah sebanyak 32 orang dari 38 responden $(84,2 \%)$.

Tabel 4 Karakteristik Responden Berdasarkan Lama Bekerja.

\begin{tabular}{cccc}
\hline No & Lama Kerja & Jumlah & Persentase \\
\hline 1 & $<1$ Tahun & 0 & $0 \%$ \\
2 & 1-3 Tahun & 7 & $18,4 \%$ \\
3 & 4-6 Tahun & 31 & $81,6 \%$ \\
4 & 7-10 Tahun & 0 & $0 \%$ \\
5 & $>10$ Tahun & 0 & $0 \%$ \\
\hline & Total & 38 & $100 \%$ \\
\hline
\end{tabular}

Berdasarkan Tabel 4, dapat diketahui bahwa hasil responden banyak didominasi oleh karyawan yang sudah bekerja antara 4-6 tahun dengan jumlah 31 orang dari 38 responden $(81,6 \%)$.

\section{Pengaruh Penerapan K3 Terhadap Kinerja Karyawan}

Untuk mengetahui apakah ada pengaruh dari penerapan K3 terhadap kinerja karyawan pabrik peneliti dapat menganalisa hasil data yang diperoleh melalui aplikasi SPSS 22, serta ada beberapa analisa dan uji yang diguanakan oleh peneliti yaitu:

a. Uji Validitas

Uji validitas merupakan sejauh mana suatu ukuran menunjukkan tingkat kevalidan suatu instrumen. Suatu item kuesioner dinyatakan valid 
apabila nilai $r_{\text {hitung }}>r_{\text {tabel }}(n-2)$. Hasil uji validitas dapat dilihat sebagai berikut:

Tabel 5. Hasil Uji Validitas Kuesioner

\begin{tabular}{|c|c|c|c|c|}
\hline Variabel & $\begin{array}{l}\text { Ite } \\
\text { m }\end{array}$ & $\begin{array}{c}r- \\
\text { hitung }\end{array}$ & $\begin{array}{c}r- \\
\text { tabel }\end{array}$ & Hasil \\
\hline \multirow{10}{*}{$\begin{array}{l}\text { Kesehatan } \\
\text { Kerja } \\
\text { (X1) }\end{array}$} & 1 & 0.499 & 0.2709 & $\begin{array}{c}\text { Valid } \\
\end{array}$ \\
\hline & 2 & 0.631 & 0.2709 & Valid \\
\hline & 3 & 0.627 & 0.2709 & Valid \\
\hline & 4 & 0.719 & 0.2709 & Valid \\
\hline & 5 & 0.724 & 0.2709 & Valid \\
\hline & 6 & 0.775 & 0.2709 & Valid \\
\hline & 7 & 0.748 & 0.2709 & Valid \\
\hline & 8 & 0.711 & 0.2709 & Valid \\
\hline & 9 & 0.688 & 0.2709 & Valid \\
\hline & 10 & 0.763 & 0.2709 & Valid \\
\hline \multirow{10}{*}{$\begin{array}{l}\text { Keselamata } \\
\text { n Kerja } \\
\text { (X2) }\end{array}$} & 1 & 0.835 & 0.2709 & Valid \\
\hline & 2 & 0.806 & 0.2709 & Valid \\
\hline & 3 & 0.522 & 0.2709 & Valid \\
\hline & 4 & 0.808 & 0.2709 & Valid \\
\hline & 5 & 0.696 & 0.2709 & Valid \\
\hline & 6 & 0.878 & 0.2709 & Valid \\
\hline & 7 & 0.858 & 0.2709 & Valid \\
\hline & 8 & 0.835 & 0.2709 & Valid \\
\hline & 9 & 0.742 & 0.2709 & Valid \\
\hline & 10 & 0.840 & 0.2709 & Valid \\
\hline \multirow{10}{*}{$\begin{array}{l}\text { Kinerja } \\
\text { Karyawan } \\
\text { (Y) }\end{array}$} & 1 & 0.555 & 0.2709 & Valid \\
\hline & 2 & 0.605 & 0.2709 & Valid \\
\hline & 3 & 0.695 & 0.2709 & Valid \\
\hline & 4 & 0.703 & 0.2709 & Valid \\
\hline & 5 & 0.509 & 0.2709 & Valid \\
\hline & 6 & 0.655 & 0.2709 & Valid \\
\hline & 7 & 0.735 & 0.2709 & Valid \\
\hline & 8 & 0.808 & 0.2709 & Valid \\
\hline & 9 & 0.802 & 0.2709 & Valid \\
\hline & 10 & 0.841 & 0.2709 & Valid \\
\hline
\end{tabular}

Dari hasil Tabel 5 di atas menunjukkan bahwa seluruh item pertanyaan memiliki corrected itemtotal correlation $\left(r_{\text {hitung }}\right)>r_{\text {tabel }}$ yaitu 0.2709 ini berarti seluruh item yang ada dinayatakan valid.

b. Uji Reliabilitas

Uji reliabilitas bertujuan untuk menguji akurasi dan ketepatan dari variabel pengukurannya. Instrument reliabel bisa menggunakan batas nilai cronbach alpha 0,60. Jika reliabilitas < 0,60 hasilnya kurang baik. Pengujian hasil reliabilitas dapat dilihat sebagai berikut:

Tabel 6. Hasil Uji Reliabilitas Kuesioner

\begin{tabular}{lcc}
\hline \multicolumn{1}{c}{ Variabel } & $\begin{array}{c}\text { Cronbach's } \\
\text { Alpha }\end{array}$ & Keterangan \\
\hline Kesehatan (X1) & 0.873 & Reliable \\
Keselamatan (X2) & 0.928 & Reliable \\
Kinerja (Y) & 0.877 & Reliable \\
\hline
\end{tabular}

Hasil uji reliabilitas pada Tabel 6 menunjukkan bahwa seluruh variabel mempunyai nilai cronbach alpha > 0,60 jadi dapat dikatakan bahwa semua variabel dari kuesioner adalah reliable.

c. Analisis Regresi Linear Berganda Analisis regresi berganda digunakan untuk menganalisa bagaimana pengaruh yang diberikan oleh variabel bebas yaitu kesehatan dan keselamatan kerja terhadap variabel terikatnya kinerja karyawan pabrik.

Tabel 7. Hasil Analisis Regresi Linear Berganda

\begin{tabular}{|c|c|c|}
\hline \multirow[t]{2}{*}{ Model } & \multicolumn{2}{|c|}{$\begin{array}{c}\text { Unstandardized } \\
\text { Coefficients }\end{array}$} \\
\hline & B & $\begin{array}{l}\text { Std. } \\
\text { Error }\end{array}$ \\
\hline (Constant) & 12.011 & 5.447 \\
\hline $\begin{array}{l}\text { Kesehatan }(\mathrm{X} 1) \\
\text { Keselamatan }(\mathrm{X} 2)\end{array}$ & $\begin{array}{l}0.352 \\
0.398 \\
\end{array}$ & $\begin{array}{l}0.200 \\
0.175 \\
\end{array}$ \\
\hline
\end{tabular}

Berdasarkan hasil output SPSS Statistic diatas menunjukkan bahwa persamaan regresi linear berganda dapat disimpulkan sebagai berikut:

$$
Y=12,011+0,352 X_{1}+0,398 X_{2}+e
$$

1) $\beta 0=12,011$

Nilai konstanta pada hasil output SPSS sebesar 12,011 hal ini dapat diiterpretasikan bahwa variabel kesehatan dan variabel keselamatan kerja tidak berubah maka kinerja karyawan adalah $12,011$. 
Widodo, M.A., Rositah, E dan Winarni, B.(2021) "Pengaruh Kesehatan Dan Keselamatan Kerja (K3) Terhadap Kinerja Karyawan Pabrik Kelapa Sawit Di PT. DSN", Jurnal Agriment, 6(2).

2) $\beta 1=0,352$

Dari hasil di atas dapat disimpulkan bahwa variabel kesehatan (X1) mempunyai pengaruh terhadap kinerja karyawan sebesar 0,352 ini artinya terdapat peningkatan kinerja karyawan secara linear sebesar 0,352 .

3) $\beta 2=0,398$

Dari hasil di atas dapat disimpulkan bahwa variabel keselamatan (X2) mempunyai pengaruh terhadap kinerja karyawan sebesar 0,398 ini artinya terdapat peningkatan kinerja karyawan secara linear sebesar 0,398 .

Berdasarkan hasil di atas maka dapat disimpulkan bahwa kedua variabel X1 dan X2 atau kesehatan dan keselamatan kerja mempunyai pengaruh positif secara bersamaan terhadap kinerja karyawan pabrik sebesar 0,750 dan meningkat secara linear.

d. Uji Simultan

Tabel 8. Hasil Output SPSS Uji F Simultan

\begin{tabular}{lcll}
\hline \multicolumn{3}{c}{ ANOVA $^{\mathrm{a}}$} \\
\hline Model & $\mathrm{F}$ & Sig. & F-Tabel \\
\hline $\begin{array}{l}\text { Regression } \\
\begin{array}{l}\text { Residual } \\
\text { Total }\end{array}\end{array}$ & 23.008 & $0.000^{\mathrm{b}}$ & 3.26 \\
\hline
\end{tabular}

Dapat dilihat dari hasil perhitungan pada Tabel 8 , hasil tersebut menunjukkan bahwa nilai $F_{\text {hitung }}$ sebesar 23,008 dengan signifikan $F \quad 0,000$ sehingga dapat disimpulkan bahwa nilai $F_{\text {hitung }}(23,008)>$ $F_{\text {tabel }}(3,26)$ dengan signifikan $F 0,000<$ 0,05 ini berarti dapat dikatakan bahwa variabel independen kesehatan (X1) dan keselamatan (X2) secara simultan berpengaruh positif dan signifikan terhadap variabel dependen kinerja karyawan $(Y)$, sehingga dapat dinyatakan hipotesa pertama diterima.

e. Koefisien Determinasi

Untuk mengetahui nilai koefesien determinasi $\left(R^{2}\right)$ pada variabel independen (bebas) terhadap variabel dependen (terikat) maka uji $\left(\mathrm{R}^{2}\right)$ dilakukan untuk mengetahui seberapa besar kemampuan variabel independen menjelaskan variabel dependen.

Tabel 9. Hasil Output SPSS Uji Determinasi

\begin{tabular}{cccc}
\hline $\mathrm{R}$ & $\begin{array}{c}\mathrm{R} \\
\text { Square }\end{array}$ & $\begin{array}{c}\text { Adjusted } \\
\mathrm{R} \text { Square }\end{array}$ & $\begin{array}{c}\text { Std. } \\
\text { Error }\end{array}$ \\
\hline $0.754^{\mathrm{a}}$ & 0.568 & 0.543 & 1.998 \\
\hline \multicolumn{4}{c}{ Berdasarkan } \\
hasil dari & Tabel 21,
\end{tabular}

diperoleh angka $\mathrm{R}$ square sebesar 0,568 . Nilai $R$ square 0,568 ini berasal dari pengkuadratan nilai koefesien korelasi $(R)$ yaitu $0,754 \times 0,754=0,568$. Besarnya angka kofesien determinasi ( $R$ square) adalah 0,568 atau sama dengan $56,8 \%$. Angka tersebut mengandung arti bahwa variabel kesehatan dan variabel keselamatan secara simultan berpengaruh terhadap variabel kinerja karyawan sebesar 56,8\% sedangkan sisanya $43,2 \%$ dipengaruh oleh faktorfaktor lain yang tidak diteliti.

Besarnya nilai koefesien determinasi atau $\mathrm{R}$ square ini umumnya berkisar antara 0-1, namun jika dalam sebuah penelitian nilai $R$ square bernilai negatif maka dapat dikatakan tidak terdapat pengaruh antara variabel dependen terhadap variabel independen. Jika nilai $R$ square semakin kecil maka artinya pengaruh varibel bebas terhadap variabel terikatnya semakin lemah, dan sebaliknya jika nilai $R$ square semakin tinggi maka pengaruh yang dihasilkan semakin kuat.

\section{PEMBAHASAN}

1. Karakteristik Responden

Dari hasil olah data pada Tabel 2, dapat dilihat bahwa persentase usia tenaga kerja tertinggi terdapat pada usia 20-29 tahun $(71,1 \%)$, pada usia $30-39$ tahun $(26,3 \%)$, dan usia 40-50 tahun $(2,6 \%)$. Dari hasil data tersebut usia yang paling dominan adalah 20-29 tahun dan usia tersebut termasuk usia produktif. Umur yang produktif mempunyai batas usia tertentu. Menurut Undang-undang Tenaga Kerja No.13 Tahun 2003 menerangkan bahwa usia produktif berada pada usia 15-64 Tahun. Hasil ini juga sejalan dengan penelitian Simamora 
(2016), bahwa tenaga kerja dengan usia 20-29 memiliki fisik yang baik dan tergolong menjadi kelompok umur produktif.

Pada Tabel 3 dapat dilihat bahwa persentase tingkat pendidikan tertinggi adalah pada tingkat SLTA $(84,2 \%)$, pada tingkat Diploma/Strata $(15,8 \%)$, tingkat SMP (0\%), dan SD (0\%). Standar pendidikan untuk pekerjaan karyawan pabrik harus memiliki tingkat pendidikan minimal SLTA, hal ini dikarenakan agar karyawan tersebut mempunyai wawasan dan pengatuhuan yang cukup luas untuk mengoprasionalkan alat-alat pabrik. Penelitian ini juga sejalan dengan penelitian Vipraprastha dan Sari (2016) mengatakan bahwa pendidikan merupakan usaha untuk meningkatkan tingkat pengetahuan.

Pada Tabel 4 dapat dilihat bahwa persentase lama kerja didominasi oleh karyawan yang sudah bekerja selama 4-6 tahun $(81,6 \%)$, lama kerja 1-3 tahun $(18,4 \%)$, lama kerja $7-10$ tahun $(0 \%)$ dan $>10$ tahun $(0 \%)$. Banyak karyawan yang sudah bekerja selama 4-6 tahun ini disebabkan karena perusahaan ini baru dibuka pada tahun 2016 sehingga perusahaan banyak menyerap tenaga kerja lokal untuk bekerja dan. Hasil ini juga sejalan dengan hasil penelitian dari Afifah dan Lubis (2016), bahwa lama kerja akan mempengaruhi tingkat keterampilan dan pengalaman kerja seseorang.

2. Pengaruh Kesehatan dan Keselamatan Terhadap Kinerja Karyawan

Dari hasil output analisis menunjukkan bahwa variabel independen (X1) dan (X2) secara bersamaan mempunyai pengaruh positif secara signifikan terhadap variabel dependen $(Y)$, sehingga pengajuan hipotesis yang diajukan yaitu terdapat pengaruh secara simultan kesehatan dan keselamatan kerja terhadap kinerja karyawan dapat diterima.

Hal ini menunjukkan bahwa program dari kesehatan dan keselamatan kerja terhadap karyawan pabrik kelapa sawit di PT. DSN memiliki K3 yang baik terhadap kinerja karyawan, ini dapat dilihat dari program kesehatan yang diberikan perusahaan kepada karyawan seperti penyediaan fasilitas poliklinik, penyediaan obat-obatan (kotak P3K) di area kerja, melakukan pemeriksaan secara berkala kepada karyawan dan memantau penyakit akibat kerja, memberikan asuransi sesuai ketentuan pemerintah berupa BPJS ketenagakerjaan, BPJS kesehatan dan BPJS pensiun, serta memberikan fasilitas hunian dan tempat kerja yang layak dan dilengkapi dengan sarana air bersih untuk menjaga kesehatan karyawanya.

Kemudian dalam program keselamatan perusahaan telah berupaya menyediakan sosialisasi penerapan K3 dengan cara safety talk setiap hari pada saat apel, safety induction dilakukan terhadap karyawan baru, safety inspection dilakukan 3 bulan sekali, dan bulan nasional K3 yang dilakukan 1 tahu sekali. Selain itu perusahaan juga telah menyediakan alat pelindung diri yang lengkap untuk karyawan mulai dari helm, safety glass, ear plug, masker, sarung tangan, pakaian seragam, dan sepatu boot. Untuk menjaga keselamatan dalam bekerja perusahaan juga menyediakan alat pemadam kebakaran (appar), alat untuk membersihkan area kerja agar tidak licin, dan memberikan rambu-rambu bahya atau peringatan disetiap stasiun.

Adapun kinerja yang dihasilkan dari program K3 tersebut diantaranya karyawan selalu bekerja sesuai dengan standar prosedur yang telah ditetapkan perusahaan, karyawan mempunyai insentitas kehadiran yang baik, dapat meyelesaikan pekerjaan sesuai dengan waktu yang ditetapkan sehingga perusahaan dapat mencapai produksinya dengan optimal yaitu dengan hasil produksi 60 ton/jam.

\section{KESIMPULAN}

Berdasarkan hasil kegiatan penelitian yang dilakukan mengenai pengaruh kesehatan dan keselamtan kerja terhadap kinerja karyawan pabrik di PT. DSN dapat disimpulkan sebagai berikut: 
1. Karakteristik responden yang bekerja di didominasi oleh usia 20-29 tahun (71,1\%), berpendidikan SLTA $(84,2 \%)$, dan sudah bekerja selama 4-6 tahun $(81,6 \%)$.

2. Kesehatan dan keselamatan mempunyai pengaruh yang positif dan signifikan terhadap kinerja karyawan pabrik kelapa sawit.

\section{DAFTAR PUSTAKA}

Afifah, S.N. dan Lubis, I. 2016. Faktor penentu produktivitas tenaga kerja kelapa sawit. Jurnal Departemen Agronomi dan Hortikultura. Fakultas Pertanian, IPB. Vol. 4, No. 2:215-223.

Anonim. 2016. Rangkuman proses pengolahan pabrik kelapa sawit. https://www.mesinpks.com (diakses pada tanggal 09 April 2020).

Anonim. 2018. Pengertian pabrik. https://id.scribid.com (diakses pada tanggal 08 April 2020).

Arikunto. 2013. Prosedur penelitian suatu pendekatan praktik. Rineka Cipta. Jakarta.

Bhuono. 2005. Strategi jitu memilih metode statistik penelitian dengan SPSS. Penerbit Abadi. Yogyakarta.

lqbal, M. 2002. Pokok-pokok materi metode penelitian dan aplikasinya. Ghalia. Jakarta.

Kuncoro, M. 2013. Metode riset untuk bisnis dan ekonomi. Erlangga. Jakarta.

Simamora. 2015. Manajemen sumber daya manusia. STIEY. Yogyakarta.

Suardi. 2007. Manajemen risiko panduan penerapan berdasarkan OHSAS 18001 dan Permenaker 05/1996. PPM. Jakarta.

Sugiyono. 2016. Metode penelitian kuantitatif, kualitatif dan R\&D. PT Alfabeth. Bandung.

Vipraprastha dan Sari, R. (2016). Pengaruh faktor-faktor kinerja individual karyawan terhadapa evektivitas. Universitas Udayana. Bali. Vol. 15, No. 3:1826-18555. 